\title{
A Review of Flexible Wearable Antenna Sensors: Design, Fabrication Methods, and Applications
}

\author{
Mariam El Gharbi ${ }^{1}\left(\mathbb{D}\right.$, Raúl Fernández-García ${ }^{1}$ (D), Saida Ahyoud ${ }^{2}$ and Ignacio Gil ${ }^{1, *(1)}$ \\ 1 Department of Electronic Engineering, Universitat Politècnica de Catalunya, 08222 Terrassa, Spain; \\ mariam.el.gharbi2@upc.edu (M.E.G.); raul.fernandez-garcia@upc.edu (R.F.-G.) \\ 2 Information Technology \& Systems Modeling Team, Faculty of Sciences, Abdelmalek Essaadi University, \\ 93002 Tetouan, Morocco; sahyoud@uae.ac.ma \\ * Correspondence: ignasi.gil@upc.edu
}

Received: 27 July 2020; Accepted: 24 August 2020; Published: 27 August 2020

\begin{abstract}
This review paper summarizes various approaches developed in the literature for antenna sensors with an emphasis on flexible solutions. The survey helps to recognize the limitations and advantages of this technology. Furthermore, it offers an overview of the main points for the development and design of flexible antenna sensors from the selection of the materials to the framing of the antenna including the different scenario applications. With regard to wearable antenna sensors deployment, a review of the textile materials that have been employed is also presented. Several examples related to human body applications of flexible antenna sensors such as the detection of $\mathrm{NaCl}$ and sugar solutions, blood and bodily variables such as temperature, strain, and finger postures are also presented. Future investigation directions and research challenges are proposed.
\end{abstract}

Keywords: antenna sensor; textile materials; wearable antenna sensor; flexible

\section{Introduction}

The industrial and academic world have generated a lot of interest in the field of wearable and flexible electronics in recent years [1]. Flexible electronics, whose mechanical properties include to be wrinkled, bent, and stressed/collapsed, would considerably extend the applications of modern electronic devices to multiple real nonflat scenarios [2], including the shape of the human body [3]. As a consequence, flexible electronics combined with textile materials offer many advantages that make them an attractive technology for boosting the next generation of consumer electronics, among them are low-cost manufacturing, inexpensive flexible substrates, light weight, and ease of fabrication [4].

Recently, there has been a lot of interest focused on antenna sensors due to their simple configuration, multimodality sensing, passive operation, and low cost [5]. Antenna sensors are electronic devices with dual functionality for communicating and sensing, and they can be implemented by minimizing the number of components. The function principle of antenna sensors is demonstrated by their geometrical or intrinsic material change influence in terms of their antenna resonance frequency, which is evaluated by means of the impact on the reflection coefficient. In addition, antenna sensors have been evolved as another process to measure diverse physical parameters. To provide the wireless communication required by today's information-oriented community, it is necessary to integrate flexible antenna sensors into flexible electronic systems [6].

In the literature, the first antenna sensor is published in [7]. A circular antenna is proposed to measure the humidity content of sludge samples. Above the antenna sensor, the sludge sample was placed inside a plastic beaker. The Bottcher model was used to calculate the humidity content of a sample from measurements of the dielectric effective permittivity of the antenna sensor. Several antenna sensors have been reported in the literature for measuring the relative permittivity of soils 
and snow [8], gas [9], relative humidity [10], $\mathrm{pH}$ [11], soil moisture [12], and glucose [13]. All of these antenna sensors can be categorized as antenna dielectric sensors. The relation between the physical measurement and the radiation parameters of the antenna is determined by the properties of the material. This issue cannot be modeled analytically in the majority of the cases [14], and it is one of the challenges of the development of antenna dielectric sensor. Therefore, almost all the reported works of antenna dielectric sensors are mainly based on direct characterization and experimental tests. With regard to antenna temperature sensors, the first one found in the literature is devoted to temperature threshold detection [15]. The antenna sensor was fabricated from a shape memory polymer (SMP) paper sandwiched between a radio frequency identification (RFID) tag and a metallic sheet. The shape memory polymer changed its relative permittivity as the temperature crossed a doorstep, which in turn could be recognized from the turn-on power of the RFID tag.

Up to now, antenna sensors are applied for many applications, such as agricultural activities and gardening, structural health, biomedical sensing, food quality monitoring, and so on, which are mostly designed on rigid materials. Several researches have already been reported in the literature using rigid materials for different types of antenna sensors, including temperature sensing [16], crack sensing [17], strain sensing [18], and dielectric sensing [19]. Microstrip patch antennas are usually employed in sensing applications because they are characterized by several advantages: low manufacturing cost, low weight, durability and reliability, and small size. Patch antennas act as sensors through the interaction between dielectric properties and electromagnetic waves. For instance, a microstrip patch antenna-based sensor using flame retardant 4 (FR-4) substrate has been presented in [20]. The proposed antenna is employed as a sensor to detect different percentage of sugar and salt in terms of return loss based on the dielectric properties of the solution. In [21], a microstrip patch antenna sensor was printed on a Rogers (R03006) substrate. The presented antenna has been designed for temperature detection by subjecting a patch antenna bonded to various metal bases to thermal cycling. These types of substrates are not quite suitable for wearable antenna sensors as they cannot be stretched and bent. A wearable antenna sensor often should have additional characteristics such as robustness and flexibility, which claims the consideration of flexible nonconventional materials to exchange traditional printed circuit boards [22].

Wearable textile antenna sensors are becoming more and more essential in on-body applications in the last decade [23], due to their ability to detect microstructure deformations and human motions and to monitor and supervise the human health $[24,25]$. Compared with conventional antenna sensors, textile antenna sensors are able to be integrated on the outfits and they offer key features such as comfort, light weight, and washability. Various wearable flexible antenna sensors have been proposed in the literature. An example of a finger motion antenna sensor based on a dipole antenna proposed to realize dual function of sensing and communicating in the wireless sensor system was presented in [26]. Moreover, this dipole antenna sensor was attached on a glove to assess the human bending impact in the actual wearable device scenario. Taking into account the previous examples and as a future trend, the antenna sensor technology could be used in human machine interfacing, healthcare, robotics, and virtual reality.

Conference proceedings and full-text articles were chosen from a comprehensive search including diverse sources and databases such as ScienceDirect, Springer, Web of Science, and IEEE Xplore. Keywords were selected in each source as follows: (wearable OR flexible) AND (textile OR electro-textile) AND antenna sensor. The initial search returned 180 results. All results were screened and analyzed to eliminate duplicates and the final total was 83 studies, of which $33.4 \%$ were focused on the classification of antenna sensors, $52.3 \%$ were associated researches on technological feasibility and reliability, and the remaining $14.3 \%$ were investigative researches on scenario-based applications.

The Section 2 details the operating principle and the types of available antenna sensors in the literature. Section 3 presents a survey of the impact of certain characteristics of textile materials, different manufacturing techniques and particular examples and applications of flexible textile antenna 
sensors. Finally, Section 4 exhibits the main conclusions and future research directions and challenges related with antenna sensors.

\section{Principle of Operation and Classification of Antenna Sensors}

\subsection{Principle of Operation}

In this section, a rectangular microstrip patch antenna is used to explain the principle of operation of an antenna sensor. A microstrip patch antenna contains four elements: a radiation patch, a dielectric substrate, a ground plane, and a transmission feed line as shown in Figure 1a. The radiation patch and the conductive ground plane (which can take any possible shape) are detached by a dielectric substrate. As a consequence, an effective electromagnetic resonance cavity allows radiation at particular frequencies [27]. The radiation patch is supplied by a microstrip feed line (Figure 1a), and an incident signal is provided. This signal is transmitted or reflected by the radiation patch. Consequently, the return loss of the microstrip patch antenna can be determined by the ratio between the reflected power and the incident power, also named "reflection coefficient" [21]. The radiation characteristics of the microstrip patch antenna can be characterized by the resonant bandwidth BW and the resonant frequency $\mathrm{f}_{0}$. These two specifications can be extracted from the reflection coefficient (S11) [28]. The operating frequency of the antenna is determined as the frequency at which the reflection coefficient is minimum, i.e., little energy is reflected by the antenna and most of the incident power is radiated [29]. The resonant bandwidth of the antenna can be defined as the range of resonant frequencies at a given return loss, e.g., at $-10 \mathrm{~dB}$. In theory, all of these radiation parameters can be used to convert a physical quantity (strain, temperature, pressure, $\mathrm{pH}$ level, concentration of aqueous solution, etc.) into a measurable radiation parameter which leads to a resonance frequency shift (see Figure 1b).

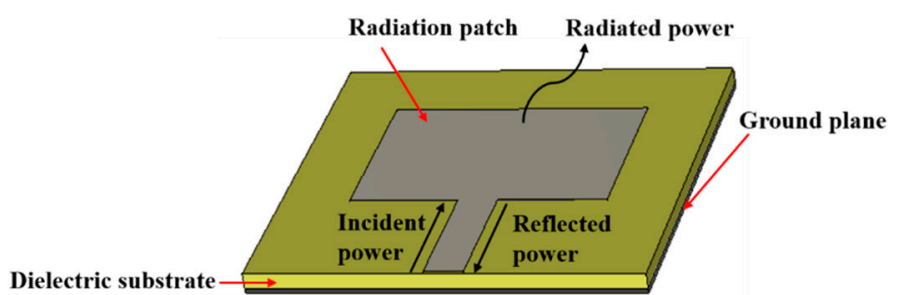

(a)

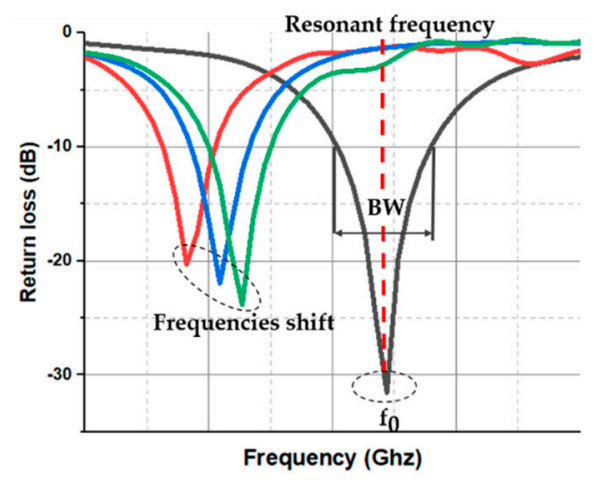

(b)

Figure 1. (a) Basic configuration of a microstrip antenna sensor and (b) illustration of frequencies shift of the antenna sensor.

\subsection{Classification of Antenna Sensors}

Antenna sensors can be classified into diverse categories as presented in the Figure 2. There are four main types of antenna sensors, namely, the temperature, dielectric, crack, and mechanical sensing. All these types of antenna sensors are able to detect changes using microwave signals or radio frequency (RF). Details of each types are described as follows.

\subsubsection{Dielectric Sensing}

An antenna dielectric sensor can be represented by a patch antenna or by other standard planar antennas. Figure 3 presents a patch antenna where the radiation patch is covered with a dielectric material (superstrate). The choice of superstrate material depends on the selected measurand (humidity, salt and sugar, gas, etc.). The substrate can use different materials such as carbon nanotubes for 
gas sensing or polymer for humidity sensing or a textile material such as denim for blood glucose sensing [30]. However, the effective dielectric constant (relative permittivity) of the antenna sensor is provided by both the superstrate and the substrate [31]. Table 1 presents a summary of previously reported works on antenna dielectric sensors with different properties such as the measurand, the size, the operation frequency, material, and the sensing parameters.

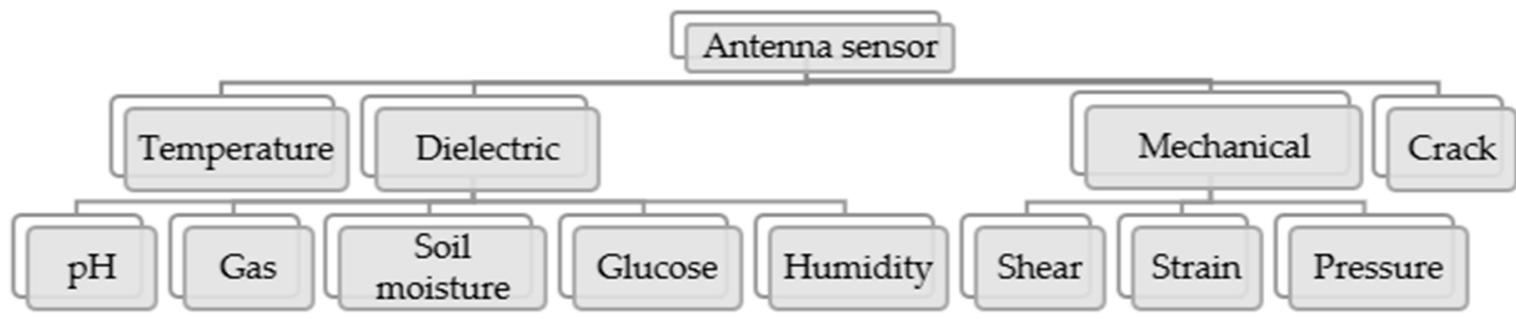

Figure 2. Different types of antenna sensors.

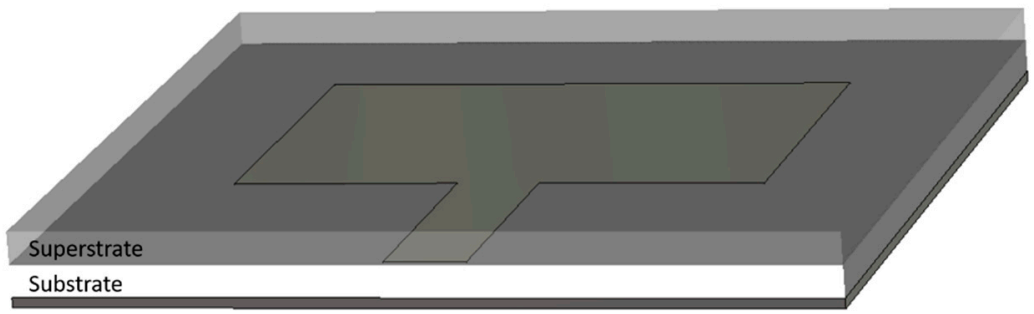

Figure 3. Configuration of an antenna dielectric sensor.

Table 1. Summary of previously reported works on antenna dielectric sensors.

\begin{tabular}{|c|c|c|c|c|c|c|c|}
\hline Ref & Measurand & $\begin{array}{c}\text { Type of } \\
\text { Antenna }\end{array}$ & $\begin{array}{c}\text { Size } \\
\left(\mathrm{mm}^{2}\right)\end{array}$ & Freq & Material & $\begin{array}{l}\text { Type of } \\
\text { Material }\end{array}$ & $\begin{array}{c}\text { Sensing } \\
\text { Parameters }\end{array}$ \\
\hline$[11]$ & $\mathrm{PH}$ & $\begin{array}{c}\text { Hexagonal } \\
\text { split-ring resonator }\end{array}$ & $19 \times 23.35$ & 3-20 GHz & ${ }^{1} \mathrm{PCB}$ & FR-4 & $\begin{array}{c}\text { Transmission } \\
\text { coefficient }\end{array}$ \\
\hline [20] & Salt and sugar & $\begin{array}{l}\text { Crescent-shaped } \\
\text { patch }\end{array}$ & $32 \times 22$ & $2.5-18 \mathrm{GHz}$ & ${ }^{1} \mathrm{PCB}$ & FR-4 & Return loss \\
\hline [32] & Humidity & H-shaped patch & $90 \times 85$ & $880 \mathrm{MHz}$ & Polymer & 2 PEDOT: PSS/ & $\begin{array}{l}\text { Threshold } \\
\text { power }\end{array}$ \\
\hline [33] & Gas & Patch antenna & $41 \times 41$ & 2.4 Ghz & ${ }^{1} \mathrm{PCB}$ & $\begin{array}{c}\text { Rogers } \\
\text { RT/duroid 5880 }\end{array}$ & Frequency shift \\
\hline [34] & Soil moisture & Spiral antenna & $12 \times 12$ & $2.48 \mathrm{GHz}$ & ${ }^{1} \mathrm{PCB}$ & FR-4 & Frequency shift \\
\hline [35] & $\begin{array}{l}\text { Moisture } \\
\text { content }\end{array}$ & Patch antenna & $48 \times 48$ & $2.26 \mathrm{GHz}$ & Polymer & ${ }^{3}$ PDMS & Frequency shift \\
\hline [36] & Humidity & Patch antenna & $30 \times 20$ & $38 \mathrm{GHz}$ & Textile & Cotton & Frequency shift \\
\hline [37] & $\begin{array}{l}\text { Relative } \\
\text { humidity }\end{array}$ & Split ring resonator & $35 \times 35$ & $0-1.5 \mathrm{GHz}$ & Polyimide & Kapton & Frequency shift \\
\hline
\end{tabular}

${ }^{1}$ Printed circuit board. ${ }^{2}$ Poly (3,4-ethylenedioxythiophene) polystyrene sulfonate. ${ }^{3}$ Polydimethylsiloxane.

\subsubsection{Strain Sensing}

In order to check the structural integrity of the engineering components, strain is among the most important mechanical properties that must be used to quantify the deformation of a material [38]. Regarding types of strains, there are two strains: shear strain and normal strain. The first type is determined from the change of angle from an original value of $90^{\circ}$ and the second type is related to the change in the size of a design compared to its original size [39]. Figure 4a shows the operating principle of an antenna sensor for shear detection. An antenna patch with a slot in the ground plane is used to visualize the effect of the shear on the behavior of the antenna. The principle of a loop antenna sensor for pressure detection is presented in Figure $4 \mathrm{~b}$. The variation of the parameter $d$ in the geometry of the antenna structure detunes its operating frequency [40].

In order to provide accurate spatial resolution, it is recommended that the strain sensor presents a small size [41]. Different types of antenna mechanical sensors are summarized in Table 2. 


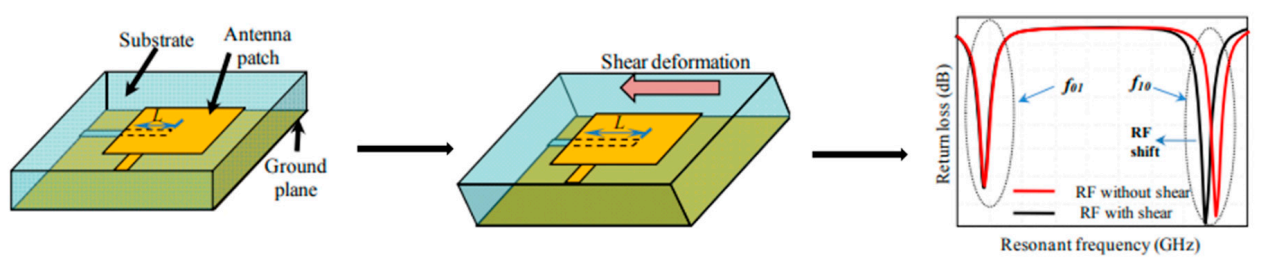

(a)
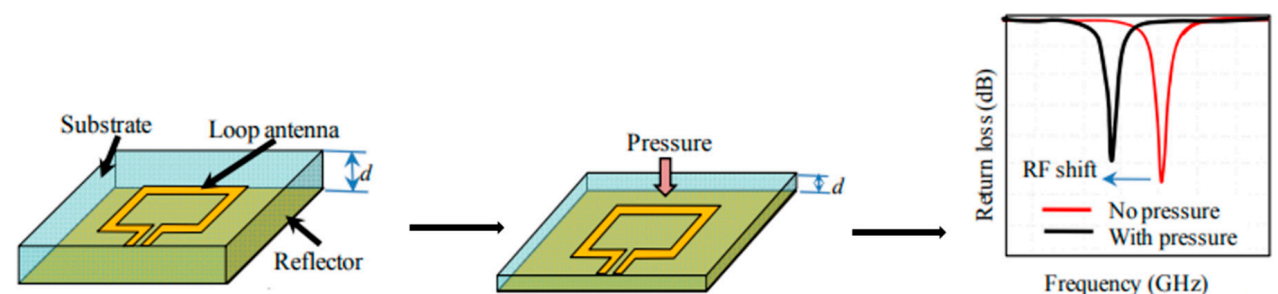

(b)

Figure 4. Antenna mechanical sensors for: (a) shear detection and (b) pressure detection, reproduced with permission from [45].

Table 2. List of antenna mechanical sensors.

\begin{tabular}{|c|c|c|c|c|c|c|c|}
\hline Ref & Measurand & $\begin{array}{c}\text { Type of } \\
\text { Antenna }\end{array}$ & Size $\left(\mathrm{mm}^{2}\right)$ & Freq & Material & $\begin{array}{c}\text { Type of } \\
\text { Material }\end{array}$ & $\begin{array}{c}\text { Sensing } \\
\text { Parameters }\end{array}$ \\
\hline [39] & Strain & Dipole antenna & $17 \times 16$ & $8-12 \mathrm{GHz}$ & Polymer & $\begin{array}{c}\text { Polyimide } \\
\text { Rogers }\end{array}$ & Frequency shift \\
\hline [42] & Pressure & Slot antenna & $17.55 \times 13.5$ & $5.5 \mathrm{GHz}$ & ${ }^{1} \mathrm{PCB}$ & $\begin{array}{l}\text { laminate } \\
\text { RO4350b }\end{array}$ & Frequency shift \\
\hline [43] & Strain & Patch antenna & $94.58 \times 52.36$ & $1.8-2.4 \mathrm{GHz}$ & Textile & Felt & Frequency shift \\
\hline [44] & $\begin{array}{l}\text { Shear and } \\
\text { pressure }\end{array}$ & Patch antenna & $12.1 \times 66.9$ & 6-7 Ghz & Polyimide & Kapton & Frequency shift \\
\hline
\end{tabular}

${ }^{1}$ Printed circuit board.

\subsubsection{Temperature Sensing}

The temperature of an antenna sensor is an important parameter to know as it indicates whether or not the antenna sensor is in control. This parameter is useful for many applications, e.g., food production, manufacturing process control, human health monitoring, etc. There are many different types of antenna temperature sensors available and all have different characteristics depending upon their application [46]. Table 3 presents some research works reported in the literature for temperature sensing with several properties: the type of the antenna sensor, the size, the operation frequency, the used materials, and the sensing parameters.

Table 3. Summary of previously reported works on antenna temperature sensors.

\begin{tabular}{|c|c|c|c|c|c|c|c|}
\hline Ref & Measurand & $\begin{array}{c}\text { Type of } \\
\text { Antenna }\end{array}$ & $\begin{array}{c}\text { Size } \\
\left(\mathrm{mm}^{2}\right)\end{array}$ & Freq & Material & $\begin{array}{c}\text { Type of } \\
\text { Material }\end{array}$ & $\begin{array}{c}\text { Sensing } \\
\text { Parameters }\end{array}$ \\
\hline [47] & Body temperature & Patch antenna & $10 \times 6$ & $38 \mathrm{GHz}$ & Textile & Cotton & Frequency shift \\
\hline [48] & Temperature & Slotted patch & $38 \times 38$ & $900 \mathrm{MHz}$ & ${ }^{1} \mathrm{PCB}$ & FR-4 & Frequency shift \\
\hline [49] & Temperature & $\begin{array}{c}\text { Rectangular } \\
\text { patch }\end{array}$ & $11.8 \times 9.8$ & $\begin{array}{l}4.85 \mathrm{GHz} \\
5.95 \mathrm{GHz}\end{array}$ & ${ }^{1} \mathrm{PCB}$ & $\begin{array}{c}\text { Rogers } \\
\text { laminate } \\
\text { RO3006 }\end{array}$ & Frequency shift \\
\hline [50] & Temperature & Patch antenna & $13.6 \times 10.9$ & $2.4-2.8 \mathrm{GHz}$ & ${ }^{1} \mathrm{PCB}$ & $\begin{array}{l}\text { Rogers } \\
\text { RO3210 }\end{array}$ & Frequency shift \\
\hline \multirow[t]{3}{*}{ [51] } & \multirow[t]{3}{*}{ Temperature } & \multirow[t]{3}{*}{ Patch antenna } & \multirow[t]{3}{*}{$71 \times 64$} & $2.45 \mathrm{GHz}$ & Textile & $\begin{array}{l}\text { Cotton } \\
\text { Jeans } \\
\text { Viscose } \\
\text { Lycra }\end{array}$ & \multirow[t]{3}{*}{ Frequency shift } \\
\hline & & & & $9.5 \mathrm{GHz}$ & & & \\
\hline & & & & $38 \mathrm{GHz}$ & & Cotton & \\
\hline
\end{tabular}

\footnotetext{
${ }^{1}$ Printed circuit board.
} 


\subsubsection{Crack Sensing}

In order to reduce catastrophic structural breakdowns, cracks must be monitored because they are a direct indicator of structural damage monitoring. In fact, it is important to know the length, direction, and location of the crack to gather sufficient information to maintain structural integrity [52]. Figure 5 presents a configuration of an antenna patch for crack detection. The direction and growth of the crack can be detected by observing the changes in the resonance frequency shifts. The resonance frequency shift of the crack antenna is generally much larger than the resonance frequency shift caused by strain or temperature [53]. Some examples for antenna crack sensors are given in Table 4.

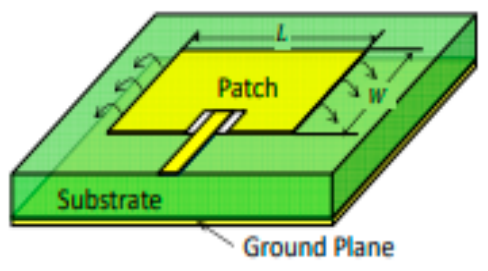

(a)

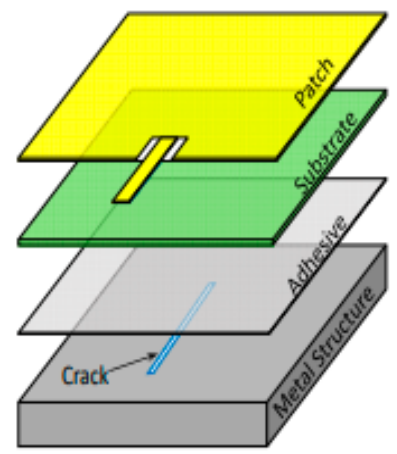

(b)

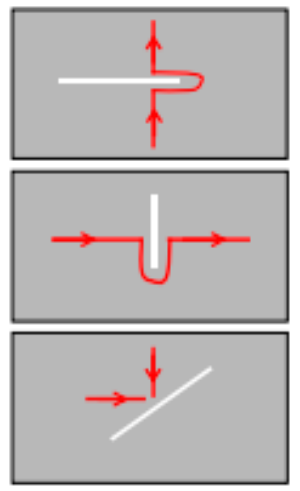

(c)

Figure 5. Antenna crack sensor: (a) schematic configuration of a patch antenna, (b) antenna sensor with crack, and (c) effect of cracks on the current model of the sensor [54].

Table 4. Summary of previously reported works on antenna crack sensors.

\begin{tabular}{|c|c|c|c|c|c|c|c|}
\hline Ref & Measurand & $\begin{array}{c}\text { Type of } \\
\text { Antenna }\end{array}$ & $\begin{array}{c}\text { Size } \\
\left(\mathrm{mm}^{2}\right)\end{array}$ & Freq & Material & $\begin{array}{c}\text { Type of } \\
\text { Material }\end{array}$ & $\begin{array}{c}\text { Sensing } \\
\text { Parameters }\end{array}$ \\
\hline [53] & $\begin{array}{c}\text { Crack } \\
\text { orientation }\end{array}$ & $\begin{array}{l}\text { Rectangular } \\
\text { patch }\end{array}$ & $15 \times 12.75$ & $\begin{array}{c}5.75 \mathrm{GHz} \\
6 \mathrm{GHz}\end{array}$ & ${ }^{1} \mathrm{PCB}$ & $\begin{array}{l}\text { Rogers laminate } \\
\text { RO4350B }\end{array}$ & $\begin{array}{l}\text { Frequency } \\
\text { shift }\end{array}$ \\
\hline [55] & $\begin{array}{l}\text { Crack opening } \\
\text { and growth }\end{array}$ & $\begin{array}{l}\text { Rectangular } \\
\text { patch }\end{array}$ & $15 \times 12.5$ & $\begin{array}{l}6.1 \mathrm{GHz} \\
8.6 \mathrm{GHz}\end{array}$ & Polyimide & Kapton & $\begin{array}{l}\text { Frequency } \\
\text { shift }\end{array}$ \\
\hline [56] & Crack & $\begin{array}{l}\text { Patch } \\
\text { antenna }\end{array}$ & $35 \times 20.6$ & $2.4 \mathrm{GHz}$ & ${ }^{1} \mathrm{PCB}$ & $\begin{array}{c}\text { Rogers } \\
\text { RT/duroid } 5880\end{array}$ & $\begin{array}{l}\text { Frequency } \\
\text { shift }\end{array}$ \\
\hline [57] & $\begin{array}{l}\text { Crack and } \\
\text { monitoring }\end{array}$ & $\begin{array}{c}\text { Patch } \\
\text { antenna }\end{array}$ & $50.8 \times 25.4$ & $\begin{array}{l}6.1 \mathrm{GHz} \\
7.6 \mathrm{GHz}\end{array}$ & Polyimide & Kapton & $\begin{array}{l}\text { Frequency } \\
\text { shift }\end{array}$ \\
\hline
\end{tabular}

${ }^{1}$ Printed circuit board.

\section{Flexible Wearable Antenna Sensor}

In order to provide good electrical performance as well as stability for the flexible devices, it is necessary to choose quality materials during manufacturing. The substrate selection for antenna sensor requires a low loss material so as to have better chances of increased antenna sensor efficiency when placed on the body. In fact, this is one of the important considerations for wearable electronics design [58]. Several flexible wearable antenna sensors are implemented on different types of materials such as papers [59], fabrics [60], and plastics [61]. Plastic substrates are neither recyclable nor biodegradable, as they affect environmental pollution and involve many health problems. Alternatively, textile materials are among the most internationally used and easily available materials for the design of flexible wearable antenna sensors with regard to body area networks (BANs). 


\subsection{Key Characteristics of Textile Materials in the Design of Antenna Sensors}

The properties of the fabrics are determined from the properties of their constituent fibers and the structure of the fabric and/or the yarns. They are fibrous and porous materials, in which the pore size, fiber density, and air volume determine the general behavior, e.g., thermal insulation and air permeability [62]. Consistently, the density and thickness of fabrics can change with pressure as they are flexible, compressible, and stretchable materials. In addition, the fibers are constantly exchanging water molecules with the surrounding environment, which can sometimes affect their shape and properties [63]. It would be difficult to control these features in textile applications and, thus, it is necessary to know the influence of these factors on the behavior of the antenna sensor to reduce the undesirable and parasitic effects. Furthermore, the impact of the properties of textile materials on the performance of the antenna sensor is presented in this section.

\subsubsection{Relative Permittivity (Dielectric Constant) of the Fabrics}

The dielectric permittivity of the substrate or material is one of the most important parameters affecting on the ability to transmit rapidly changing signals through the textile transmission line. The operation frequency and reflection coefficient in the transmission line can be affected by this phenomenon. The dielectric permittivity is defined as Equation (1):

$$
\varepsilon=\varepsilon_{0} \varepsilon_{\mathrm{r}}=\varepsilon_{0}\left(\varepsilon_{\mathrm{r}}^{\prime}-\mathrm{j} \varepsilon_{\mathrm{r}}^{\prime \prime}\right)
$$

where $\varepsilon_{0}=8.854 \times 10-12 \mathrm{~F} / \mathrm{m}$ is the permittivity of vacuum [64]. Generally, the moisture content, the temperature, the frequency, and also the surface roughness depend on the dielectric properties of the material under test [65]. The real part of the dielectric constant, $\varepsilon_{\mathrm{r}}^{\prime}$, is also named "the relative permittivity". It should be noted that this parameter is not constant in frequency. In addition, the material losses are typically given by the loss tangent, defined as $\tan \delta=\varepsilon_{\mathrm{r}}^{\prime \prime} / \varepsilon_{\mathrm{r}}^{\prime}$.

The dielectric properties of textiles are reviewed and studied in $[66,67]$. The textile materials dielectric behavior depends on the characteristics of the constituent polymers and fibers. Various experimental methods have been used to determine an accurate measurement of the dielectric characteristics of textiles. Among these techniques, there are the cavity perturbation method [68], the MoM-segment method [69], the free-space method [70], and the transmission line method [71]. Generally, textiles offer a very low relative permittivity (in comparison with typical rigid substrate materials for electronic applications) as they are very porous fabrics. Table 5 presents the dielectric properties of common commercial textile fabrics.

Table 5. Dielectric properties of normal fabrics. Data from reference [72].

\begin{tabular}{ccc}
\hline Nonconductive Fabric & $\varepsilon_{\mathbf{r}}$ & $\tan \delta$ \\
\hline Cordura $^{(r)}$ & 1.90 & 0.0098 \\
Cotton & 1.6 & 0.0400 \\
$100 \%$ polyester & 1.90 & 0.0045 \\
Quartzel $^{(r)}$ fabric & 1.95 & 0.0004 \\
Felt & $1.215-1.225$ & 0.016 \\
Silk & 1.75 & 0.012 \\
Jeans & 1.7 & 0.025 \\
Fleece & 1.17 & 0.0035 \\
Denim & $1.6-1.65$ & 0.05 \\
\hline
\end{tabular}

\subsubsection{Surface Resistivity of Fabrics}

The electronic performance of fabrics can be determined by the surface resistance. Hence, the surface resistance is the ratio of a direct voltage applied to the current obtained from two electrodes placed on the surface of a material [73], and it also can be defined by the ratio between the DC voltage drop 
per unit length and the surface current per unit width. Surface resistivity is thus a property of the fabric considering a constant thickness, not depending on the design of the electrodes used for the measurement [62]. It is usually indicated by Ohm/square $(\Omega / \mathrm{sq})$.

\subsubsection{Regain of the Fabrics}

Relative humidity (RH) of the fabrics is determined as the amount of water in a sample of air compared to the maximum amount of water the air can hold at a given temperature. It is expressed in a form of $0 \%$ to $100 \%$ [74]. In [65], some studies are presented on various textile fibers which indicate the relationship between relative humidity of the air and regain (amount of humidity present in a fabric calculated as a percentage of its oven-dry weight). Note that for the same relative humidity conditions, there are textile fibers with different humidity contents. For example, at $65 \% \mathrm{RH}$, cotton fiber could offer a regain of $7.5 \%$, polyester fiber might offer a regain of $0.2 \%$, and wool fiber might offer a regain of $14.5 \%$ [65]. Generally, the humidity absorption changes the properties of fibers, such as the effective permittivity or the mechanical rigidity. For this reason, fabric metrology is carried out at a specified temperature of $20^{\circ} \mathrm{C}$ and relative humidity of $65 \%$ [62].

\subsubsection{Mechanical Deformations of the Fabrics}

Textile fabrics are characterized by their good elasticity and flexibility, which makes them adaptive to curvature of the human body. However, after adapting to the topology of the surface, the structure is usually deformed and bent. These geometrical modifications influence the performance of the antenna sensor and they also lead to changes in the electromagnetic properties of textile fabrics [75]. In fact, the elongation and the bending of the dielectric fabric affect their thickness and their effective permittivity, which influences the resonance frequency of the antenna sensor. Furthermore, when the antenna sensor is compressed or elongated, the geometric accuracy decreases, affecting the behavior of the antenna sensor and, as a result, a resonant frequency shift can be produced.

\subsection{Fabrication Methods for Wearable Antenna Sensor}

Fabrication techniques are the determinants of the accuracy and manufacturing speed of low-cost wearable antenna sensor designs. The most popular wearable fabrication techniques are listed as follows: wet-etching [75], screen printing [76], inkjet printing [77], and embroidery methods [78]. To ensure durability, low cost, and high comfort to users in their daily wear, these techniques can be used for antenna sensors fabrication. An interesting review of these manufacturing methods is presented in [79-81]. Several of the aforementioned manufacturing techniques are discussed below.

\subsubsection{Screen Printing}

To produce a lightweight and flexible antenna sensor, screen printing is a simple and economical approach used by many electronics manufacturers. In addition, the screen printing is an additive operation, which makes it environmentally friendly [82]. Instead of hiding the woven screen that has different thread densities and thicknesses, the mask with the required pattern is adjusted directly to the substrate where the conductive ink is handled and thermally annealed.

Moreover, the screen-printing technique faces diverse limitations. It comprises its limited number of realizable layers, lack of thickness control for the conductive layer, and low printing resolution. These aspects lead to the limited implementation of this technology, because wearable printing requires better precision for the convenient operation of the communications for wearable devices.

\subsubsection{Inkjet Printing}

Inkjet printing is one of the relatively low-cost printing technologies [83]. This technology is capable of producing a very high precision pattern due to its use of ink droplets of the size of up to a few picoliters [84]. Additionally, this technique allows the design pattern to be transmitted directly to 
the substrate with no requirement for masks. In addition, inkjet printing projects the single ink droplet from the nozzle to the required position, from which no waste is founded, which makes it among the economical manufacturing methods. This is a clear advantage in comparison with traditional etching technology, which has been generally used in industry [85]. The main drawbacks of inkjet printing technology are the incompatibility of certain types of conductive inks due to the larger particle size and clogging of the nozzles. Figure 6 presents an example of the inkjet-printing method using electroconductive layers on the surface of textile.

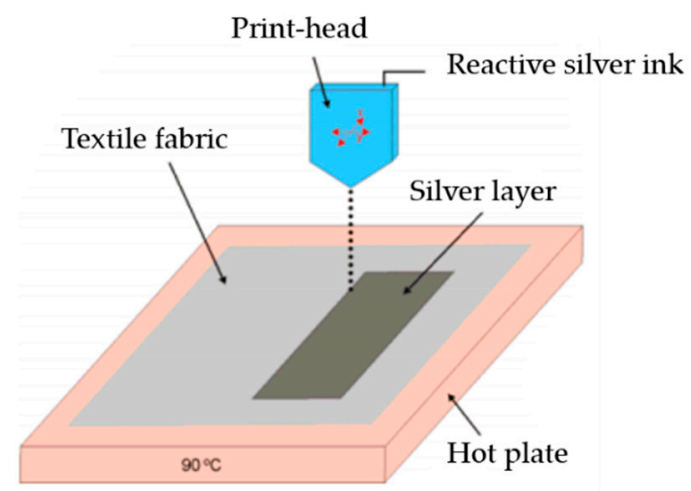

Figure 6. Silver deposition on textile surface using inkjet printing, reproduced with permission from [86].

\subsubsection{Embroidery}

This technique has been evolved to allow a digital image or layout to be directly embroidered using a computer-assisted embroidery machine. The embroidery manufacturing uses specialized conductive threads, from which the antenna sensor can be embroidered on the base substrate textile fabric. Before embroidering, it is very important to know the properties of the conductive threads that are going to be used (conductivity, DC resistance, and mechanical parameters), because when the conductive thread is characterized, it is then easier to find methods to improve the performance of the antenna sensor [87]. Therefore, the conductive threads must have adequate resistance and flexibility to avoid undesired breaks produced by high tensions in the embroidery machine [88]. Figure 7 depicts the embroidery technique, starting with the simulated design model to embroider the antenna integrated with the textile substrate.

Although embroidered antenna sensors are greatly considered as an ideal solution to replace traditional antennas in flexible electronics, compared with antenna sensors fabricate of metallic materials, they present some limitations, e.g., the embroidered geometry is much stretchable than metallic antenna sensors on inlays. This stretching impact, combined with the low resolution of the yarn stitches, makes fine geometries impractical [89]. The resistance of conductive yarn is much higher than metallic materials. They are either made of nylon cores coated with silver plating or carbon. The resistivity of the antenna sensors made from these yarns is order-of-magnitude higher than metallic ones even printed ones (made of silver paste or made of aluminum or copper).

\subsubsection{Comparison of Embroidery with Other Techniques}

The embroidery process is advantageous over other techniques and embroidery machines are more recommended in the industry. This technique is easier to apply for mass production of clothing with integrated embroidered antenna sensors. In embroidery, the currents in the fabric flow along the yarns, making linear antenna sensors such as spirals or dipoles suitable for this fabrication technique, because it is very difficult to manufacture this type of structure using a Nora dell cloths or copper tape. With embroidery, the use of glue is not always a requirement to connect the textile layers together and also it allows to create reproducible geometries via computerized embroidery machines [91]. This can improve the washability of the clothing with the integrated antenna sensor. 


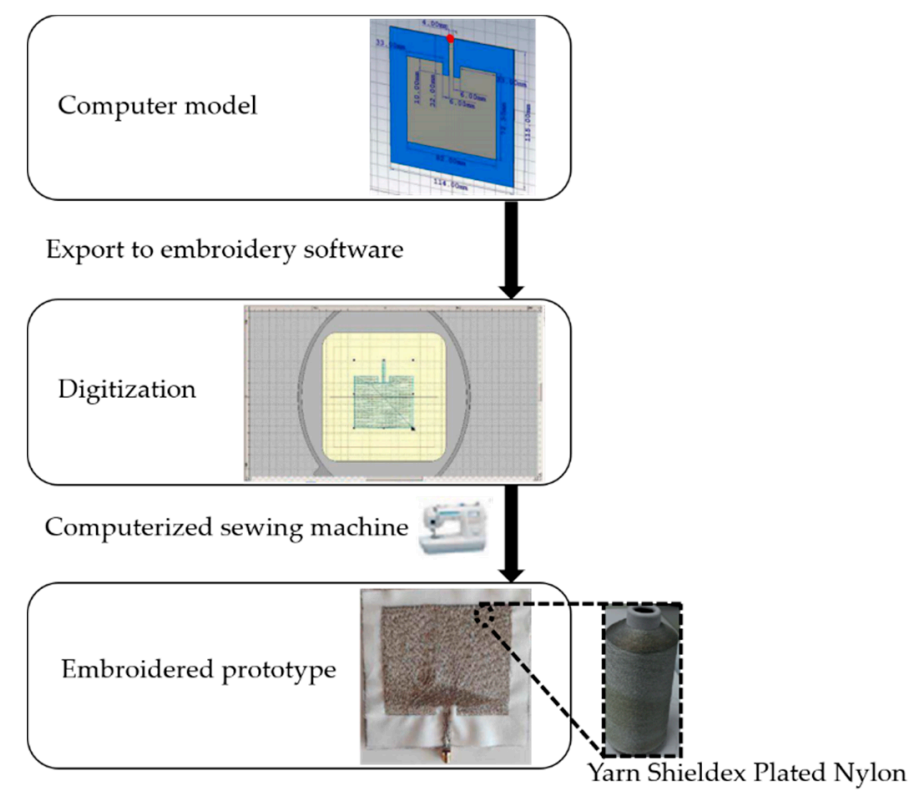

Figure 7. Embroidery process, reproduced with permission from [90].

\subsection{Alternative Materials for the Deployment of Flexible Antenna Sensors}

Various flexible wearable antenna sensors are implemented on different types of materials such as Kapton polyimide [92], cellulose filter paper [93], polydimethylsiloxane (PDMS) film [94], and graphene film (FGF) [95]. These materials are being applied as promising candidates for innovative flexible antenna sensors. All of these antenna sensors are discussed in the next section. Furthermore, the graphene has attracted tremendous interest in wearable communication devices due to its outstanding electronic properties and performance. However, the applications of graphene in antenna sensors are limited because the use of single or few layer graphene films exhibit insufficient electrical conductivity and high sheet resistance. Figure 8 represents the manufacturing process of an antenna sensor. This antenna is fabricated on a cellulose paper substrate with a radiating patch of aluminum tape and a ground plane.

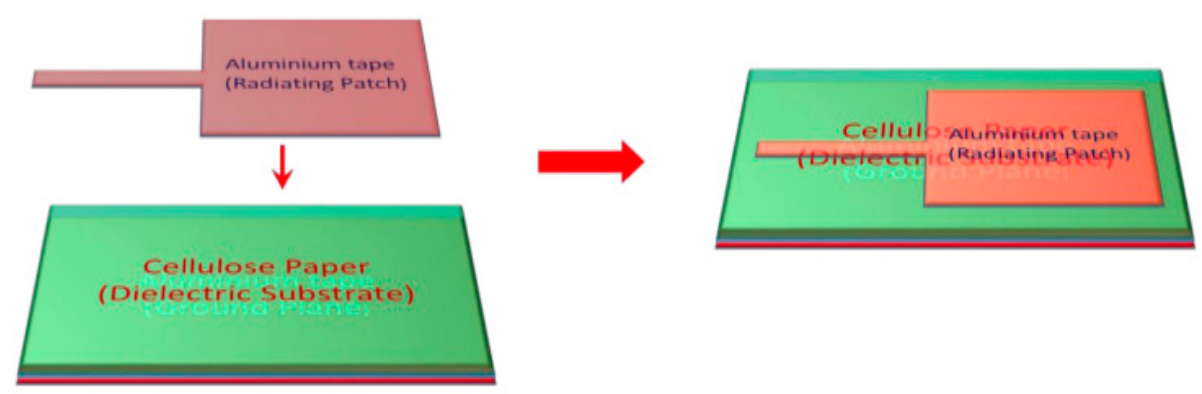

Figure 8. Manufacturing process of rectangular patch antenna sensor, reproduced with permission from [96].

\subsection{Applications and Specific Examples of Flexible Textile Antenna Sensor Designs}

In current society, sensing applications are always based on some specific scenarios, which require different functions for the antenna sensors. Flexible antenna sensors are an attracted research orientation in the field, and there are some typical samples as listed in Table 6, including dipole antenna sensors [26], patch antenna sensors [93,95-98], and RFID tag sensors [99,100].

A cellulose filter paper substrate for liquids detection was presented as shown in Figure 9b [93]. The patch antenna sensor utilized the special feature of the paper substrate, which is capable of absorbing liquids, such as sweat on the skin. The dielectric constant of the paper substrate is sensitive 
to the properties of the absorbed liquid through the 2 slots in the structure. In this paper, the feasibility of the sweat detection is validated by artificial sweat and salt solutions measurements, in which the frequency mainly shifted with changing $\mathrm{NaCl}$ (sodium chloride) concentration $(8.5-200 \mathrm{mmol} / \mathrm{L}$ ).

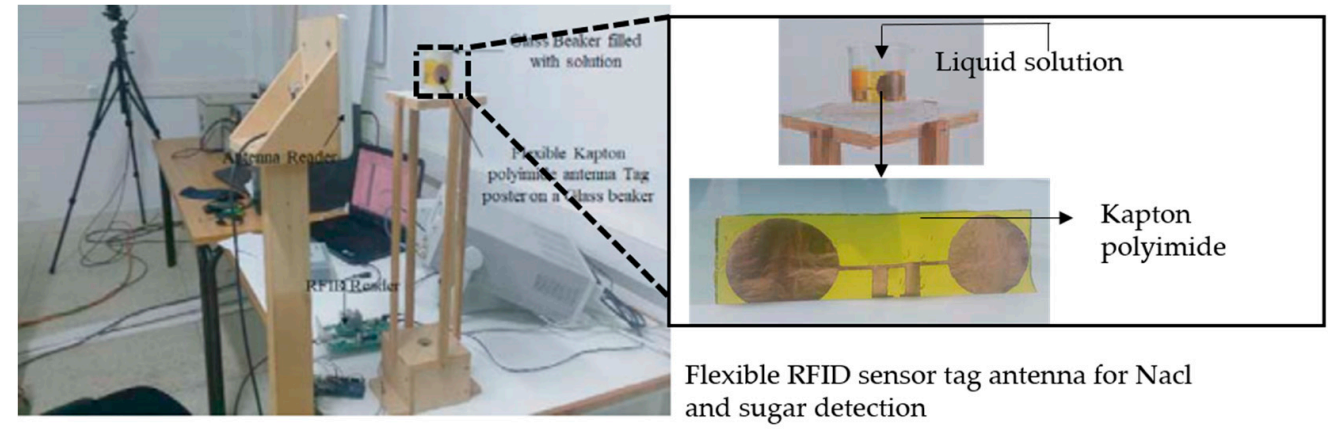

(a)

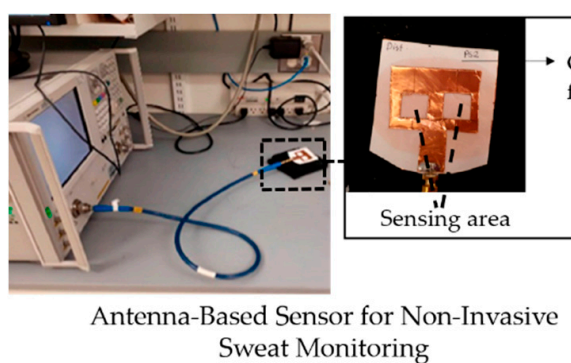

(b)

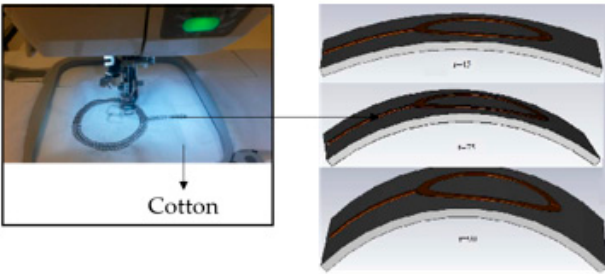

Textile wearable antenna sensor based on Open Ring Resonators

(c)

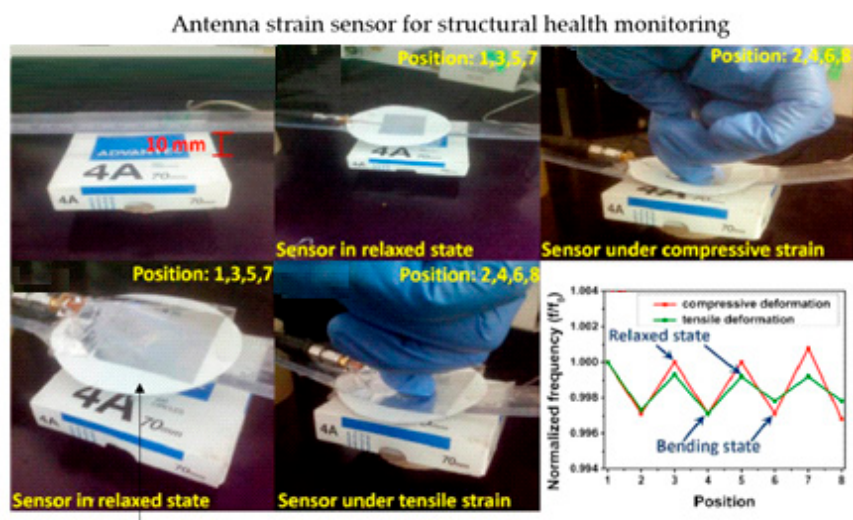

Cellulose filter paper

(d)

Figure 9. (a) Experimental setup for the measurements of the concentration of aqueous solutions, reproduced by courtesy of The Electromagnetics Academy [99]; (b) antenna sensor photo after absorbing saline solution [93]; (c) antenna sensor under bending stress, reproduced with permission from [101]; and (d) photographs of an antenna sensor in state tensile strain and compressive, reproduced with permission from [96].

Compared with the mentioned flexible based antenna sensor for solution detection, another antenna sensor with RFID techniques [99] was designed to detect the concentration of $\mathrm{NaCl}$ (sodium chloride) solutions and sucrose solutions, which was printed on a polyimide substrate as shown in Figure 9a. The proposed RFID tag antenna was used to detect the solutions based on sensitivity to different levels of concentration. From tests with concentration levels from $0 \%$ to $80 \%$ at the different 
frequency points $(864,868,915$, and $926 \mathrm{MHz})$, the results revealed that sensitivity increases with the rise of concentration levels of $\mathrm{NaCl}$ and sucrose solutions.

Table 6. List of some previously reported work of flexible textile antenna sensor.

\begin{tabular}{|c|c|c|c|c|c|c|c|}
\hline Ref & Measurand & $\begin{array}{c}\text { Type of } \\
\text { Antenna }\end{array}$ & $\begin{array}{c}\text { Size } \\
\left(\mathrm{mm}^{2}\right)\end{array}$ & Freq & Material & Type of Material & $\begin{array}{c}\text { Sensing } \\
\text { Parameters }\end{array}$ \\
\hline$[26]$ & $\begin{array}{c}\text { Finger } \\
\text { postures }\end{array}$ & Dipole antenna & $100 \times 20$ & $426 \mathrm{MHz}$ & Filter paper & Cellulose filter paper & Frequency shift \\
\hline [93] & $\begin{array}{c}\text { Noninvasive } \\
\text { Sweat }\end{array}$ & Patch antenna & $50 \times 60$ & $2-4 \mathrm{GHz}$ & Filter paper & Cellulose filter paper & Frequency shift \\
\hline [95] & Strain & Patch antenna & $35 \times 27.4$ & $1.63 \mathrm{GHz}$ & Carbon & Graphene Film (FGF) & Frequency shift \\
\hline [96] & Strain & Patch antenna & $29.5 \times 37.7$ & $2.4 \mathrm{GHz}$ & Filter paper & Cellulose filter paper & Frequency shift \\
\hline [98] & Temperature & Patch antenna & $71 \times 64$ & $2.45 \mathrm{GHz}$ & Textile & Cotton & Frequency shift \\
\hline [99] & $\begin{array}{l}\mathrm{NaCl} \text { and } \\
\text { sugar }\end{array}$ & RFID tag & $100 \times 32$ & $860-960 \mathrm{MHz}$ & Polyimide & Kapton & Frequency shift \\
\hline [100] & Strain & RFID tag & $100 \times 20$ & $866.6 \mathrm{MHz}$ & Textile & Polyester & Frequency shift \\
\hline
\end{tabular}

For the body fluids detection field, another typical textile-based antenna sensor was proposed for the blood glucose monitoring as shown in Table 6 [97]. This proposed antenna sensor was designed to operate at $2.4 \mathrm{GHz}$ in a noninvasive manner. In this work, the SAR analysis was taken into account since the antenna sensor would radiate towards the body when operating on the arm. In addition, the work revealed the SAR was also sensitive to the substrate thickness. For instance, when the thickness value was $4 \mathrm{~mm}$, the SAR value would be $3.86 \mathrm{~W} / \mathrm{kg}$, which was lower than the safety limit value of $4 \mathrm{~W} / \mathrm{kg}$.

A microstrip patch antenna sensor was designed to detect temperature as detailed in Table 6 [98]. The proposed antenna sensor was embroidered on a cotton substrate and developed to operate at ISM band around $2.45 \mathrm{GHz}$. In this work, the relative permittivity of the substrate sensitive to the temperature was utilized to affect the resonant frequency points. Through this way, the low-cost solution for heat monitoring could be used for body temperature detection.

A textile-based antenna sensor was proposed for the research on bending impact as shown in Figure 9c [101]. This proposed antenna sensor was designed with an open ring resonator structure, which was sensitive to the bending levels of the structure. In this work, the antenna sensor was tested under different bending radius $(45$ and $90 \mathrm{~mm}$ ) and results showed an output sensitivity from 0.4 to $2.2 \mathrm{MHz} / \mathrm{mm}$. The feasibility and usefulness could be validated for developments of the antenna sensor based on textile materials with an open ring resonator structure.

A paper-based patch antenna sensor was proposed for strain detection as shown in Figure 9d [96]. The antenna sensor was fabricated by a radiation patch as the antenna and sensor, a layer of cellulose filter paper as the substrate, and an aluminum tape as the ground pane. In this work, after hundreds of bending cycles in the bending strain tests, the performance of the antenna sensor was still stable. In addition, through small cracks identification, bending angle analysis, and real human motion detection applied to gloves, the antenna sensor was fully evaluated and proved to be feasible to be used in medical, healthcare, and modern electronic device areas.

A graphene-based antenna sensor was proposed for high strain detection as listed in Table 6 [95]. This antenna sensor was designed to operate at $1.63 \mathrm{GHz}$ with the flexible multilayer graphene film (FGF) whose conductivity reaches $106 \mathrm{~S} / \mathrm{m}$. In this work, the performance of the proposed antenna sensor with the special material was tested under tensile and compressive bending situations, respectively. In addition, compared with the antenna sensor with similar copper material, the strain sensitivity of the graphene-based antenna sensor was higher. The kind of antenna sensor had some good features in reversible deformability, mechanical flexibility, and structure stability, which made it suitable for some applications such as wireless strain sensing and wearable devices. 


\section{Conclusions and Future Research Directions}

In the realization and implementation of wearable devices, flexible antenna sensors are getting more attention due to their conformal characteristics, lightweight, and low cost, being ideal for wireless communication and sensing applications. This review starts with the principle of operation and the types of antenna sensors used and their state-of-the-art including technologies to realize these devices. For any presented type, divers reference examples are provided. Next, a survey of the effect of some features of the wearable materials, including dielectrics and conductors, in the behavior of the antenna sensors is reported. The work also details some guidelines for the choice of materials for designing textile antenna sensors. The current advanced manufacturing techniques for flexible wearable antenna sensors are discussed. Finally, several applications and specific examples of flexible wearable antenna sensor designs are reviewed. Flexible antenna sensors are promising devices to enhance and boost the development of wireless communication technology and contribute to the miniaturization and improvement of performance of the future communication systems, especially with regard to wearable applications and human body area network scenarios.

Flexible wearable antenna sensors are a topic of increasing interest for industry and the scientific community. For this reason, some research key issues and challenges foreseen for future research in this area are presented as follows:

- Improving the precision and efficiency of the current manufacturing and measuring methods.

- Introducing new yarns and conductive fabrics in the market with less resistivity or higher conductivity.

- Introducing new flexible wearable materials for embroidery technique or new proposed manufacturing techniques.

- Introducing new antenna sensors based on textile substrates to operate on body.

Textile antenna sensors are expected to be used in various fields such as industry, healthcare, security, and so on. In addition, it is still a long way for wearable antenna sensors to improve their performance and increase their reliability in future applications. Further research is still needed to explore novel designs with new manufacturing processes and textile materials. New materials such as graphene and conductive ink on textile substrates have been employed in order to improve the performance of textile sensors and are promising candidates for next-generation antenna sensors.

Textile antenna sensors present great potential applications in many areas of life and production. In fact, the reported research in the scientific literature is mainly focused on the basic functions of textile antenna sensors such as humidity sensing, temperature sensing, and strain sensing. Nowadays, there are some uses for the textile antenna sensors that do not cover advanced functions and significant research is in progress. For example, there are wearable textile antenna sensors that can only detect the temperature without analyzing any other element such as bending and reliability, which requires more research. In addition, textile antenna sensors are more suitable for different applications such as for medical applications due to the various medical textiles employed for elderly or patients. Many types of parameters including moisture, strain, blood-glucose, and $\mathrm{pH}$ could be detected by means of textile antenna sensor systems. As a consequence, numerous scenarios could create many opportunities for new designs and applications of textile antenna sensors in the future.

Author Contributions: M.E.G. conducted the research and writing, I.G. and R.F.-G. supervised and reviewed the work, whereas S.A. collaborated in writing and review of the paper. All authors have read and agreed to the published version of the manuscript.

Funding: This work was supported by the Spanish Government-MINECO under Projects TEC2016-79465-R.

Conflicts of Interest: The authors declare no conflict of interest. 


\section{References}

1. Venkatesan, M.; Veeramuthu, L.; Liang, F.-C.; Chen, W.-C.; Cho, C.-J.; Chen, C.-W.; Chen, J.-Y.; Yan, Y.; Chang, S.-H.; Kuo, C.-C. Evolution of electrospun nanofibers fluorescent and colorimetric sensors for environmental toxicants, $\mathrm{pH}$, temperature, and cancer cells-A review with insights on applications. Chem. Eng. J. 2020, 397, 125413. [CrossRef]

2. Lim, C.; Shin, Y.; Jung, J.; Kim, J.H.; Lee, S.; Kim, D.-H. Stretchable conductive nanocomposite based on alginate hydrogel and silver nanowires for wearable electronics. APL Mater. 2019, 7, 31502. [CrossRef]

3. Wang, G.; Hou, C.; Wang, H. Flexible and Wearable Electronics for Smart Clothing; John Wiley \& Sons: Hoboken, NJ, USA, 2020.

4. Nathan, A.; Chalamala, B.R. Special issue on flexible electronics technology, Part 1: Systems and applications. Proc. IEEE 2005, 93, 1235-1238. [CrossRef]

5. Huang, H. Flexible wireless antenna sensor: A review. IEEE Sens. J. 2013, 13, 3865-3872. [CrossRef]

6. Feliu-Batlle, V.; Feliu-Talegon, D.; Castillo-Berrio, C.F. Improved object detection using a robotic sensing antenna with vibration damping control. Sensors 2017, 17, 852. [CrossRef]

7. Gagnadre, I.; Gagnadre, C.; Fenelon, J.P. Circular patch antenna sensor for moisture content measurement on dielectric material. Electron. Lett. 1995, 31, 1167-1168. [CrossRef]

8. Denoth, A. The monopole-antenna: A practical snow and soil wetness sensor. IEEE Trans. Geosci. Remote Sens. 1997, 35, 1371-1375. [CrossRef]

9. McGrath, M.P.; Sabouni, R.N.; Pham, A.-V.H. Development of nanobased resonator gas sensors for wireless sensing systems. Nano Sens. Mater. Devices 2004, 5593, 62-72.

10. Chang, K.; Kim, Y.-H.; Kim, Y.-J.; Yoon, Y.J. Patch antenna using synthesized polyimide for RFID sensing. In Proceedings of the 2006 European Conference on Wireless Technology, Manchester, UK, 10-12 September 2006; pp. 83-86.

11. Islam, M.T.; Ashraf, F.B.; Alam, T.; Misran, N.; Mat, K.B. A compact ultrawideband antenna based on hexagonal split-ring resonator for $\mathrm{pH}$ sensor application. Sensors 2018, 18, 2959. [CrossRef]

12. You, K.Y.; Salleh, J.; Abbas, Z.; You, L.L. A rectangular patch antenna technique for the determination of moisture content in soil. Prog. Electromagn. Res. C 2010, 850-854. Available online: https://www.researchgate.net/publication/236615978_A_Rectangular_Patch_Antenna_Technique_ for_the_Determination_of_Moisture_Content_in_Soil (accessed on 2 June 2020).

13. Wiwatwithaya, S.; Phasukkit, P.; Tungjitkusolmun, S.; Wongtrairat, W. Real-time monitoring glucose by used microwave antenna apply to biosensor. In Proceedings of the 4th 2011 Biomedical Engineering International Conference, Shanghai, China, 15-17 October 2011; pp. 135-137.

14. Huang, H.; Chen, Z.N. Antenna sensors in passive wireless sensing systems. In Handbook of Antenna Technologies; Springer: Singapore, 2015; pp. 1-34.

15. Bhattacharyya, R.; Floerkemeier, C.; Sarma, S.; Deavours, D. RFID tag antenna based temperature sensing in the frequency domain. In Proceedings of the 2011 IEEE International Conference on RFID, Orlando, FL, USA, 12-14 April 2011; pp. 70-77.

16. Rodrigues, D.B.; Maccarini, P.F.; Salachi, S.; Oliveira, T.R.; Pereira, P.J.S.; Limão-Vieira, P.; Snow, B.W.; Reudink, D.; Stauffer, P.R. Design and optimization of an ultra wideband and compact microwave antenna for radiometric monitoring of brain temperature. IEEE Trans. Biomed. Eng. 2014, 61, 2154-2160. [CrossRef]

17. Padmavathy, T.V.; Bhargava, D.S.; Venkatesh, P.; Sivakumar, N. Design and development of microstrip patch antenna with circular and rectangular slot for structural health monitoring. Pers. Ubiquitous Comput. 2018, 22, 5-6. [CrossRef]

18. Tchafa, F.M.; Huang, H. Microstrip patch antenna for simultaneous strain and temperature sensing. Smart Mater. Struct. 2018, 27, 65019. [CrossRef]

19. Cheng, E.M.; Fareq, M.; Shahriman, A.B.; Mohd Afendi, R.; Lee, Y.S.; Khor, S.F.; Tan, W.H.; Nashrul Fazli, M.N.; Abdullah, A.Z.; Jusoh, M.A. Development of microstrip patch antenna sensing system for salinity and sugar detection in water. Int. J. Mech. Mechatron. Eng. 2014, 15, 31-36.

20. Islam, M.T.; Rahman, M.N.; Singh, M.S.J.; Samsuzzaman, M. Detection of salt and sugar contents in water on the basis of dielectric properties using microstrip antenna-based sensor. IEEE Access 2018, 6, 4118-4126. [CrossRef] 
21. Sanders, J.W.; Yao, J.; Huang, H. Microstrip patch antenna temperature sensor. IEEE Sens. J. 2015, 15, 5312-5319. [CrossRef]

22. Luo, C.; Gil, I.; Fernández-García, R. Wearable textile UHF-RFID sensors: A systematic review. Materials 2020, 13, 3292. [CrossRef]

23. Paracha, K.N.; Rahim, S.K.A.; Soh, P.J.; Khalily, M. Wearable antennas: A review of materials, structures, and innovative features for autonomous communication and sensing. IEEE Access 2019, 7, 56694-56712. [CrossRef]

24. Liu, Y.; Wang, H.; Zhao, W.; Zhang, M.; Qin, H.; Xie, Y. Flexible, stretchable sensors for wearable health monitoring: Sensing mechanisms, materials, fabrication strategies and features. Sensors 2018, 18, 645. [CrossRef]

25. Azeez, H.I.; Yang, H.-C.; Chen, W.-S. Wearable triband E-shaped dipole antenna with low SAR for IoT applications. Electronics 2019, 8, 665. [CrossRef]

26. Su, C.; Wu, H. An Antenna Sensor to Identify Finger Postures. In Proceedings of the 2019 IEEE Eurasia Conference on IOT, Communication and Engineering (ECICE), Yunlin, Taiwan, 3-6 October 2019; pp. 571-574.

27. Yang, J.; Wang, H.; Lv, Z.; Wang, H. Design of miniaturized dual-band microstrip antenna for WLAN application. Sensors 2016, 16, 983. [CrossRef]

28. Balanis, C.A. Microstrip antennas. Antenna Theory Anal. Des. 2005, 3, 811-882.

29. Howell, J.Q. Microstrip antennas. ITAP 1975, 23, 90-93. [CrossRef]

30. Cioffi, V.; Costanzo, S. Wearable approach for contactless blood-glucose monitoring by textile antenna sensor. In Proceedings of the World Conference on Information Systems and Technologies, La Toja Island, Spain, 16-19 April 2019; pp. 287-291.

31. Islam, M.T.; Ullah, M.H.; Singh, M.J.; Faruque, M.R.I. A new metasurface superstrate structure for antenna performance enhancement. Materials 2013, 6, 3226-3240. [CrossRef]

32. Manzari, S.; Occhiuzzi, C.; Nawale, S.; Catini, A.; di Natale, C.; Marrocco, G. Humidity sensing by polymer-loaded UHF RFID antennas. IEEE Sens. J. 2012, 12, 2851-2858. [CrossRef]

33. Verma, R.; Said, K.; Salim, J.; Kimathi, E.; Rizkalla, M.; Shrestha, S.; Agarwal, M.; Varahramyan, K. Carbon nanotube-based microstrip antenna gas sensor. In Proceedings of the 2013 IEEE 56th International Midwest Symposium on Circuits and Systems (MWSCAS), Columbus, OH, USA, 4-7 August 2013; pp. 724-727.

34. Priyaa, A.S.P.; Mohammed, A.; Ambili, C.; Anusree, N.S.; Thekekara, A.V.; Rajesh Mohan, R.; Mridula, S. Microwave Sensor Antenna for Soil Moisture Measurement. In Proceedings of the 2015 Fifth International Conference on Advances in Computing and Communications (ICACC), Kochi, India, 3-5 September 2015; pp. 258-262.

35. Zhu, L.; Li, W.; Han, X.; Peng, Y. Microfluidic flexible substrate integrated microstrip antenna sensor for sensing of moisture content in lubricating oil. Int. J. Antennas Propag. 2020, 2020. [CrossRef]

36. Lin, X.; Seet, B.-C.; Joseph, F. Wearable humidity sensing antenna for BAN applications over $5 \mathrm{G}$ networks. In Proceedings of the 2018 IEEE 19th Wireless and Microwave Technology Conference (WAMICON), Sand Key, FL, USA, 9-10 April 2018; pp. 1-4.

37. Akhir, S.A.M.; Ibrahim, S.Z.; Rosli, N.; Zain, A.S.M.; Khalid, N. Antenna for humidity sensor using split ring resonator. Indones. J. Electr. Eng. Comput. Sci. 2019, 13, 584-592. [CrossRef]

38. Mattelin, M.-A.; Missinne, J.; de Coensel, B.; van Steenberge, G. Imprinted polymer-based guided mode resonance grating strain sensors. Sensors 2020, 20, 3221. [CrossRef]

39. Jang, S.-D.; Kim, J. Passive wireless structural health monitoring sensor made with a flexible planar dipole antenna. Smart Mater. Struct. 2012, 21, 27001. [CrossRef]

40. Lopato, P.; Herbko, M. A circular microstrip antenna sensor for direction sensitive strain evaluation. Sensors 2018, 18, 310. [CrossRef]

41. Zhang, J.; Tian, G.Y.; Marindra, A.M.J.; Sunny, A.I.; Zhao, A.B. A review of passive RFID tag antenna-based sensors and systems for structural health monitoring applications. Sensors 2017, 17, 265. [CrossRef]

42. Yao, J.; Xu, C.C.; Mears, A.; Jaguan, M.; Tjuatja, S.; Huang, H. Pressure sensing using low-cost microstrip antenna sensor. Sens. Smart Struct. Technol. Civ. Mech. Aerosp. Syst. 2015, 9435, 943537.

43. Omer, H.A.H.; Azemi, S.N.; Al-Hadi, A.A.; Soh, P.J.; Jamlos, M.F. Structural health monitoring sensor based on a flexible microstrip patch antenna. Indones. J. Electr. Eng. Comp. Sci. 2018, 10, 917-924. [CrossRef]

44. Huang, H.; Farahanipad, F.; Singh, A.K. A stacked dual-frequency microstrip patch antenna for simultaneous shear and pressure displacement sensing. IEEE Sens. J. 2017, 7, 8314-8323. [CrossRef] 
45. Mohammad, I.; Huang, H. Pressure and shear sensing based on microstrip antennas. In Sensors and Smart Structures Technologies for Civil, Mechanical, and Aerospace Systems 2012; Society of Photo-Optical Instrumentation Engineers (SPIE): Bellingham, WA, USA, 2012; p. 83451D.

46. Goumopoulos, C. A high precision, wireless temperature measurement system for pervasive computing applications. Sensors 2018, 18, 3445. [CrossRef] [PubMed]

47. Lin, X.; Seet, B.-C.; Joseph, F. Fabric antenna with body temperature sensing for BAN applications over 5G wireless systems. In Proceedings of the 2015 9th International Conference on Sensing Technology (ICST), Auckland, New Zealand, 8-10 December 2015; pp. 591-595.

48. Yang, F.; Qiao, Q.; Virtanen, J.; Elsherbeni, A.Z.; Ukkonen, L.; Sydanheimo, L. Reconfigurable sensing antenna: A slotted patch design with temperature sensation. IEEE Antennas Wirel. Propag. Lett. 2012, 11, 632-635. [CrossRef]

49. Jiang, H.; Sanders, J.; Yao, J.; Huang, H. Patch antenna based temperature sensor. Nondestructive Characterization for Composite Materials, Aerospace Engineering, Civil Infrastructure, and Homeland Security 2014; The International Society for Optical Engineering: Bellingham, WA, USA, 2014; p. 90631P.

50. Tchafa, F.M.; Huang, H. Microstrip patch antenna for simultaneous temperature sensing and superstrate characterization. Smart Mater. Struct. 2019, 28, 105009. [CrossRef]

51. Ibanez-Labiano, I.; Alomainy, A. Dielectric characterization of non-conductive fabrics for temperature sensing through resonating antenna structures. Materials 2020, 13, 1271. [CrossRef]

52. Zhang, J.; Huang, B.; Zhang, G.; Tian, G.Y. Wireless passive ultra high frequency RFID antenna sensor for surface crack monitoring and quantitative analysis. Sensors 2018, 18, 2130. [CrossRef]

53. Mohammad, I.; Gowda, V.; Zhai, H.; Huang, H. Detecting crack orientation using patch antenna sensors. Meas. Sci. Technol. 2011, 23, 15102. [CrossRef]

54. Ke, L.; Liu, Z.; Yu, H. Characterization of a patch antenna sensor's resonant frequency response in identifying the notch-shaped cracks on metal structure. Sensors 2019, 19, 110. [CrossRef]

55. Mohammad, I.; Huang, H. Monitoring fatigue crack growth and opening using antenna sensors. Smart Mater. Struct. 2010, 19, 55023.

56. Xue, S.; Yi, Z.; Xie, L.; Wan, G.; Ding, T. A passive wireless crack sensor based on patch antenna with overlapping sub-patch. Sensors 2019, 19, 4327. [CrossRef] [PubMed]

57. Mohammad, I.; Huang, H. An antenna sensor for crack detection and monitoring. Adv. Struct. Eng. 2011, 14, 47-53. [CrossRef]

58. Hatamie, A.; Angizi, S.; Kumar, S.; Pandey, C.M.; Simchi, A.; Willander, M.; Malhotra, B.D. Textile based chemical and physical sensors for healthcare monitoring. J. Electrochem. Soc. 2020, 167, 37546. [CrossRef]

59. Marasco, I.; Niro, G.; Lamanna, L.; Piro, L.; Guido, F.; Algieri, L.; Mastronardi, V.M.; Qualtieri, A.; Scarpa, E.; Desmaele, D.; et al. Compact and flexible meander antenna for Surface Acoustic Wave sensors. Microelectron. Eng. 2020, 227, 111322. [CrossRef]

60. Wagih, M.; Wei, Y.; Komolafe, A.; Torah, R.; Beeby, S. Reliable UHF long-range textile-integrated RFID tag based on a compact flexible antenna filament. Sensors 2020, 20, 3435. [CrossRef]

61. Ossa, O.D.; Lopez, F.E. Rectangular patch antenna strain sensor with plastic substrate for curvature measurements. IEEE Lat. Am. Trans. 2018, 16, 1358-1363. [CrossRef]

62. Salvado, R.; Loss, C.; Gonçalves, R.; Pinho, P. Textile materials for the design of wearable antennas: A survey. Sensors 2012, 12, 15841-15857. [CrossRef]

63. Liu, N.; Lu, Y.; Qiu, S.; Li, P. Electromagnetic properties of electro-textiles for wearable antennas applications. Front. Electr. Electron. Eng. China 2011, 6, 563-566. [CrossRef]

64. Baker-Jarvis, J.; Janezic, M.D.; DeGroot, D.C. High-frequency dielectric measurements. IEEE Instrum. Meas. Mag. 2010, 13, 24-31. [CrossRef]

65. Hearle, J.W.S.; Morton, W.E. Physical Properties of Textile Fibres; Elsevier: Amsterdam, The Netherlands, 2008.

66. Bal, K.; Kothari, V.K. Measurement of dielectric properties of textile materials and their applications. NOPR 2009, 34, 191-199.

67. Sankaralingam, S.; Gupta, B. Determination of dielectric constant of fabric materials and their use as substrates for design and development of antennas for wearable applications. IEEE Trans. Instrum. Meas. 2010, 59, 3122-3130. [CrossRef]

68. Ouyang, Y.; Chappell, W.J. High frequency properties of electro-textiles for wearable antenna applications. IEEE Trans. Antennas Propag. 2008, 56, 381-389. [CrossRef] 
69. Shawl, R.K.; Longj, B.R.; Werner, D.H.; Gavrin, A. The characterization of conductive textile materials intended for radio frequency applications. IEEE Antennas Propag. Mag. 2007, 49, 28-40. [CrossRef]

70. Harmer, S.W.; Rezgui, N.; Bowring, N.; Luklinska, Z.; Ren, G. Determination of the complex permittivity of textiles and leather in the 14-40 GHz millimetre-wave band using a free-wave transmittance only method. IET Microw. Antennas Propag. 2008, 2, 606-614. [CrossRef]

71. Declercq, F.; Rogier, H.; Hertleer, C. Permittivity and loss tangent characterization for garment antennas based on a new matrix-pencil two-line method. IEEE Trans. Antennas Propag. 2008, 6, 2548-2554. [CrossRef]

72. Cicchetti, R.; Miozzi, E.; Testa, O. Wideband and UWB antennas for wireless applications: A comprehensive review. Int. J. Antennas Propag. 2017, 2017, 1-45. [CrossRef]

73. Petersen, P.; Helmer, R.; Pate, M.; Eichhoff, J. Electronic textile resistor design and fabric resistivity characterization. Text. Res. J. 2011, 81, 1395-1404. [CrossRef]

74. Dhupkariya, S.; Singh, V.K.; Shukla, A. A review of textile materials for wearable antenna. J. Microw. Eng. Technol. 2015, 1, 975-8887.

75. Locher, I.; Klemm, M.; Kirstein, T.; Troster, G. Design and characterization of purely textile patch antennas. IEEE Trans. Adv. Packag. 2006, 29, 777-788. [CrossRef]

76. Roshni, S.B.; Jayakrishnan, M.P.; Mohanan, P.; Surendran, K.P. Design and fabrication of an E-shaped wearable textile antenna on PVB-coated hydrophobic polyester fabric. Smart Mater. Struct. 2017, 26, 105011. [CrossRef]

77. Abutarboush, H.F.; Farooqui, M.F.; Shamim, A. Inkjet-printed wideband antenna on resin-coated paper substrate for curved wireless devices. IEEE Antennas Wirel. Propag. Lett. 2015, 15, 20-23. [CrossRef]

78. Tsolis, A.; Whittow, W.G.; Alexandridis, A.A.; Vardaxoglou, J.C. Embroidery and related manufacturing techniques for wearable antennas: Challenges and opportunities. Electronics 2014, 3, 314-338. [CrossRef]

79. Seager, R.; Zhang, S.; Chauraya, A.; Whittow, W.; Vardaxoglou, Y.; Acti, T.; Dias, T. Effect of the fabrication parameters on the performance of embroidered antennas. IET Microw. Antennas Propag. 2013, 7, 1174-1181. [CrossRef]

80. Rogier, H. Textile antenna systems: Design, fabrication, and characterization. In Handbook of Smart Textiles; Springer: Singapore, 2015; pp. 433-458.

81. Aun, N.F.M.; Soh, P.J.; Al-Hadi, A.A.; Jamlos, M.F.; Vandenbosch, G.A.E.; Schreurs, D. Revolutionizing wearables for 5G: 5G technologies: Recent developments and future perspectives for wearable devices and antennas. IEEE Microw. Mag. 2017, 18, 108-124. [CrossRef]

82. Khaleel, H.R. Design and fabrication of compact inkjet printed antennas for integration within flexible and wearable electronics. IEEE Trans. Compon. Packag. Manuf. Technol. 2014, 4, 1722-1728. [CrossRef]

83. Wang, Y.; Yan, C.; Cheng, S.-Y.; Xu, Z.-Q.; Sun, X.; Xu, Y.-H.; Chen, J.-J.; Jiang, Z.; Liang, K.; Feng, Z.-S. Flexible RFID Tag Metal Antenna on Paper-Based Substrate by Inkjet Printing Technology. Adv. Funct. Mater. 2019, 29, 1902579. [CrossRef]

84. Lakafosis, V.; Rida, A.; Vyas, R.; Yang, L.; Nikolaou, S.; Tentzeris, M.M. Progress towards the first wireless sensor networks consisting of inkjet-printed, paper-based RFID-enabled sensor tags. Proc. IEEE 2010, 98, 1601-1609. [CrossRef]

85. Yang, L.; Rida, A.; Vyas, R.; Tentzeris, M.M. RFID tag and RF structures on a paper substrate using inkjet-printing technology. IEEE Trans. Microw. Theory Tech. 2007, 55, 2894-2901. [CrossRef]

86. Stempien, Z.; Rybicki, E.; Rybicki, T.; Lesnikowski, J. Inkjet-printing deposition of silver electro-conductive layers on textile substrates at low sintering temperature by using an aqueous silver ions-containing ink for textronic applications. Sens. Actuators B Chem. 2016, 224, 714-725. [CrossRef]

87. Acti, T.; Zhang, S.; Chauraya, A.; Whittow, W.; Seager, R.; Dias, T. High performance flexible fabric electronics for megahertz frequency communications. In Proceedings of the 2011 Loughborough Antennas \& Propagation Conference, Laughborough, UK, 14-25 November 2011; pp. 1-4.

88. Wang, Z.; Lee, L.Z.; Psychoudakis, D.; Volakis, J.L. Embroidered multiband body-worn antenna for GSM/PCS/WLAN communications. IEEE Trans. Antennas Propag. 2014, 62, 3321-3329. [CrossRef]

89. Liu, Y.; Xu, L.; Li, Y.; Ye, T.T. Textile based embroidery-friendly RFID antenna design techniques. In Proceedings of the 2019 IEEE International Conference on RFID (RFID), Pisa, Italy, 25-27 September 2019; pp. 1-6. 
90. Gil, I.; Fernandez-Garcia, R. Wearable embroidered GPS textile antenna. In Proceedings of the 2017 Progress in Electromagnetics Research Symposium-Spring (PIERS), St. Petersburg, Russia, 22-25 May 2017; pp. 655-659.

91. Kaufmann, T.; Fumeaux, I.-M.; Fumeau, C.X. Comparison of fabric and embroidered dipole antennas. In Proceedings of the 2013 7th European Conference on Antennas and Propagation (EuCAP), Gorhenburg, Swiden, 8-12 April 2013; pp. 3252-3255.

92. el Khamlichi, M.; Melcon, A.A.; el Mrabet, O.; Ennasar, M.A.; Hinojosa, J. Flexible UHF RFID tag for blood tubes monitoring. Sensors 2019, 19, 4903. [CrossRef] [PubMed]

93. Eldamak, A.R.; Fear, E.C. Conformal and disposable antenna-based sensor for non-invasive sweat monitoring. Sensors 2018, 18, 4088. [CrossRef]

94. Xu, F.; Zhang, D.; Liao, Y.; Xie, F.; Zhang, H. Dispersion of LiZnTiBi ferrite particles into PMDS film for miniaturized flexible antenna application. Ceram. Int. 2019, 45, 8914-8918. [CrossRef]

95. Tang, D.; Xu, L.; Li, Y.; Ye, T.T. Highly sensitive wearable sensor based on a flexible multi-layer graphene film antenna. Sci. Bull. 2018, 63, 574-579. [CrossRef]

96. Kanaparthi, S.; Sekhar, V.R.; Badhulika, S. Flexible, eco-friendly and highly sensitive paper antenna based electromechanical sensor for wireless human motion detection and structural health monitoring. Extrem. Mech. Lett. 2016, 9, 324-330. [CrossRef]

97. Costanzo, S.; Cioffi, V. Preliminary SAR Analysis of Textile Antenna Sensor for Non-invasive Blood-Glucose Monitoring. In Proceedings of the International Conference on Information Technology \& Systems, Bogotá, Colombia, 5-7 February 2020; pp. 607-612.

98. Labiano, I.I.; Alomainy, A. Fabric Antenna for Temperature Sensing over ISM Frequency Band. In Proceedings of the 2019 IEEE International Symposium on Antennas and Propagation and USNC-URSI Radio Science Meeting, Atlanta, GA, USA, 7-12 July 2019; pp. 1567-1568.

99. Ennasar, M.A.; el Mrabet, O.; Mohamed, K.; Essaaidi, M. Design and characterization of a broadband flexible polyimide RFID tag sensor for $\mathrm{NaCl}$ and sugar detection. Prog. Electromagn. Res. 2019, 94, $273-283$. [CrossRef]

100. Chen, X.; Ukkonen, L.; Björninen, T. Passive E-textile UHF RFID-based wireless strain sensors with integrated references. IEEE Sens. J. 2016, 16, 7835-7836. [CrossRef]

101. Moradi, B.; Fernández-García, R.; Gil, I. Textile wearable antenna sensors based on open ring resonators. In Proceedings of the 12th European Conference on Antennas and Propagation (EuCAP), London, UK, 9-13 April 2018.

(C) 2020 by the authors. Licensee MDPI, Basel, Switzerland. This article is an open access article distributed under the terms and conditions of the Creative Commons Attribution (CC BY) license (http://creativecommons.org/licenses/by/4.0/). 